\title{
Leiomyoma
}

\section{An unusual tumour of the orbit}

\author{
F. A. JAKOBIEG, I. S. JONES, AND M. TANNENBAUM
}

From the Departments of Ophthalmology and Pathology, College of Physicians and Surgeons, Columbia University, New York, V.Y. гоo32, U.S.A.

Leiomyoma of the orbit, a benign tumour of smooth muscle, is exceedingly rare (Reese, I963; Offret and Haye, I97I). Furthermore, its diagnosis is suspect when one fails to demonstrate non-striated cytoplasmic filaments convincingly. The present case is reported for three reasons:

(I) It is the only orbital leiomyoma in the files of the Eye Institute;

(2) It has a well-documented clinical course spanning ro years;

(3) The tumour was initially misdiagnosed as a fibrous histiocytoma.

\section{Case report}

A generally healthy I7-year-old white youth attended his local ophthalmologist in I963 with proptosis of the right eye of unknown duration. The Hertel readings were $22 \mathrm{~mm}$. in the right eye and $\mathrm{I} 6 \mathrm{~mm}$. in the left. The eye examination was negative except for some limitation of upward gaze on the right. It was decided that he had a benign intraconal lesion and should be followed.

Dr. Pfeiffer saw the patient at the Eye Institute in 1965 , when the Hertel reading was $27 \mathrm{~mm}$. in the right eye. A partial excisional biopsy was performed and the sections were interpreted by Dr. Arthur Purdy Stout as a fibrous histiocytoma. The proptosis regressed only slightly after the procedure. In 1969 the patient was referred to the Massachusetts General Hospital for consideration of radiotherapy. The Pathology Department reviewed the histology and inclined towards a diagnosis of fibroma of uncertain aetiology and discouraged radiotherapy.

In December, I97 I, the patient was seen by Dr. I. S. Jones. The globe was displaced forwards, down, and out, with Hertel readings of $34 \mathrm{~mm}$. in the right eye and $19 \mathrm{~mm}$. in the left (Fig. I).

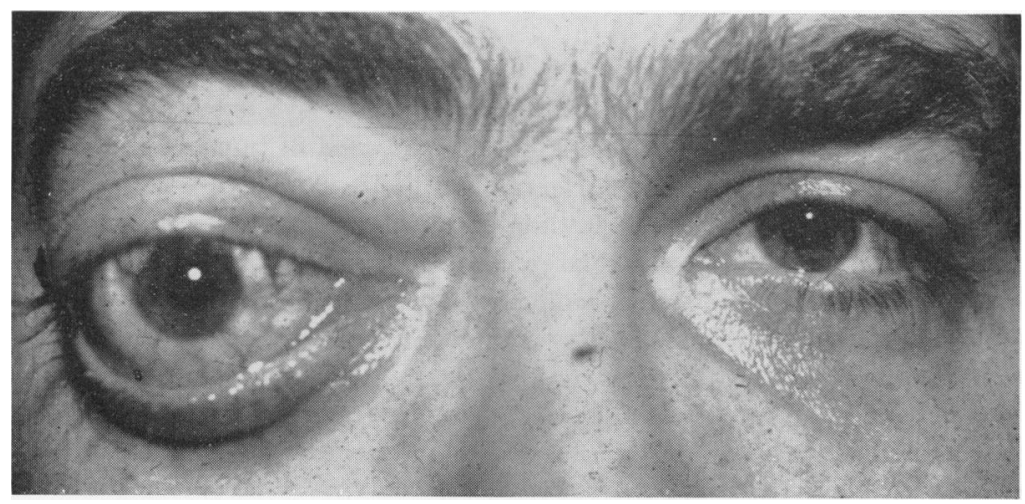

FIG. I Proptosed right globe, preoperatively in December, I97 I 
The visual acuity was 20 . 20 in each eye with faint vertical striae in the right fundus. A movable. lobulated soft mass was palpated above the right globe. There were dilated episcleral vessels fiom 210.5 o'clock. (Ocular movements in the right eye were limited in all directions. The visual fields were full. Ultrasonography disclosed an acoustically solid mass surrounding the optic nerve. extending $20 \mathrm{~mm}$. antero-posteriorly and indenting the globe (Fig. 2). The orbital apex was clear. Hypocycloidal tomography demonstrated a smooth fossa in the right central orbital roof. which was quite thin but without any evidence of communication with the frontal sinus (Fig. 3 .
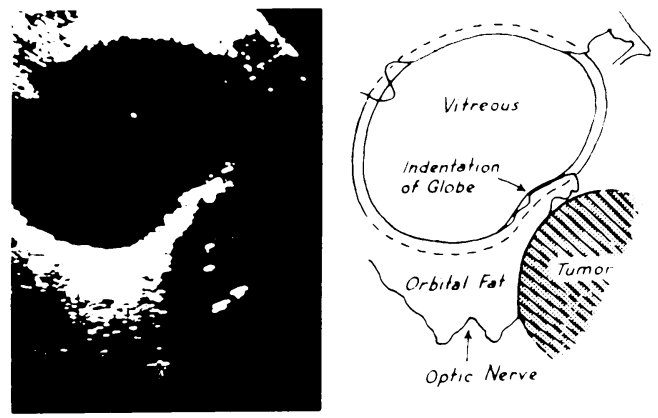

FI (;. 2 P-ultrasonogram of orbital tumour icourtesy' of I)r. I) Fackison Cioleman

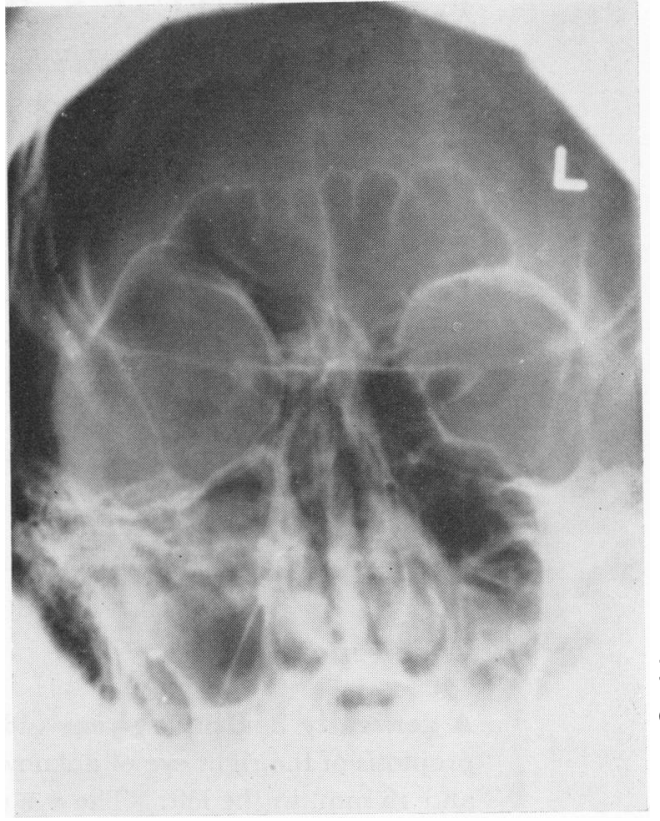

A Kronlein operation was performed by Inr. Jones who found a multilobulated mass occupying the superior aspect of the orbit and extending towards the apex as well as down the sides of the ortbit nasally and temporally. There was a definite capsule present which had to be torn during surgery in order to remove the tumour from around the optic nerve. The tumour bled considerably. About two ounces or 80 per cent. of the tumour was remored: the tumour was fiable. breaking up into small pieces as it was enucleated.

The patient was seen in follow-up by his local ophthalmologist on March 21, I972. Fxophthalmometry yielded $19 \mathrm{~mm}$. in the right eye and $18 \mathrm{~mm}$. in the left. There was $3 \mathrm{~mm}$. of right ptosis.

The visual acuity was 20/20 in each eye. The propriety of radiotherapy for the residual tumour was again raised but. in view of the complete surgical removal, radiotherapy was not given.

LI I : H M ICROSCOPY

Microscopic sections from the tumour specimens of 1965 and 197 I are identical and the following description applies equally to both. The tumour is composed of bundles of spindle cells often in whirl or curlicue patterns (Fig. 4). The nuclei of the cells are elongated with blunted tips and there are very rare mitotic figures (Fig. 5). Palisading of nuclei and herringbone patterns are also found in different fields. The tumour contains a large number of dilated capillaries. Masson's trichrome stain reveals minimal amounts of interstitial collagen while reticulin stain shows an orderly deposition of small amounts of reticulin between the cells. Both the trichrome and PTAH stains fail to highlight any cytoplasmic filaments or give a red reaction. In cross-section. some of the cells show haloes around the nuclei, where the cytoplasm appears to have contracted. One area of the tumour with a particularly dense collection of capillary passages shows a pseudo-haemangiopericytomatous pattern (Fig. 6, overleaf. 


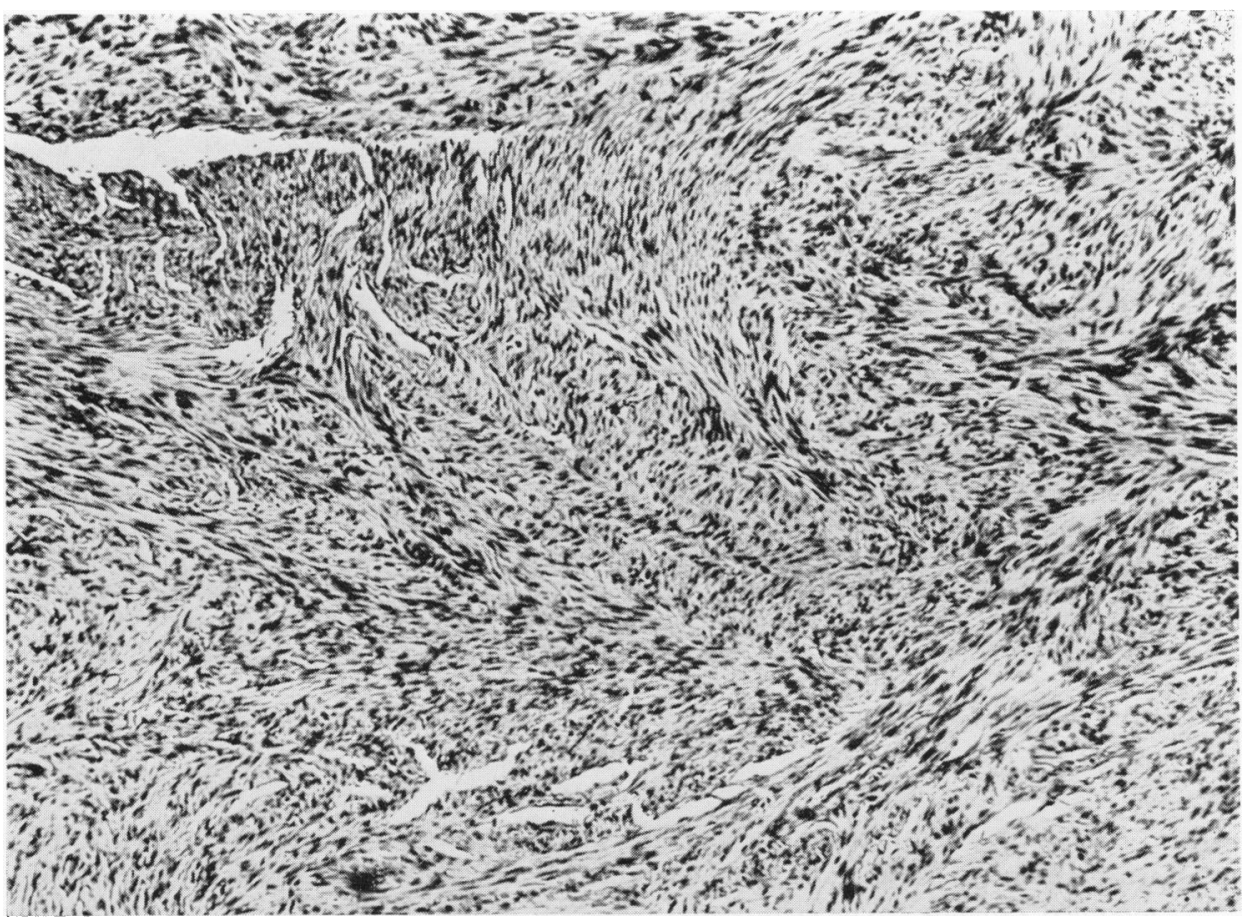

FIG. 4 Characteristic tumour field, showing bursting effect of narrow cellular fascicles, palisading of nuclei, and dilated capillary channels. Haematoxylin and eosin. $\quad \times 80$

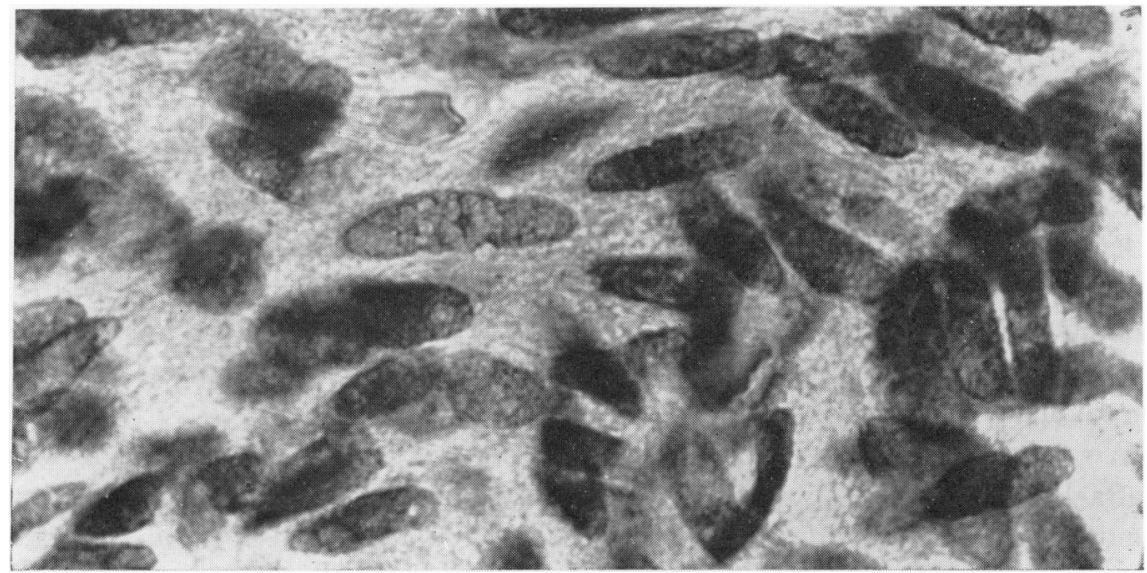

FIG. 5 Cigar-shaped nuclei. Haematoxylin and eosin. $\times 600$

\section{ELECTRON MICROSCOPY}

Fresh tissue was fixed in 2.5 per cent. glutaraldehyde with $0_{1}$ I $M$ phosphate buffer $(\mathrm{pH} 7 \cdot 4)$. The tissue was refrigerated at $4^{\circ} \mathrm{C}$. Dehydration in graded alcohols and propylene oxide, at room temperature, was followed by embedding in epon and polymerization overnight at $65^{\circ} \mathrm{C}$. Ultrathin sections were cut on a Porter-Blum microtome with a diamond knife. Bare copper grids, Sjöstrand type, were used. Sections were stained with uranyl acetate and lead citrate and finally carboncoated. Micrographs were taken on a Siemens IA electron microscope. 


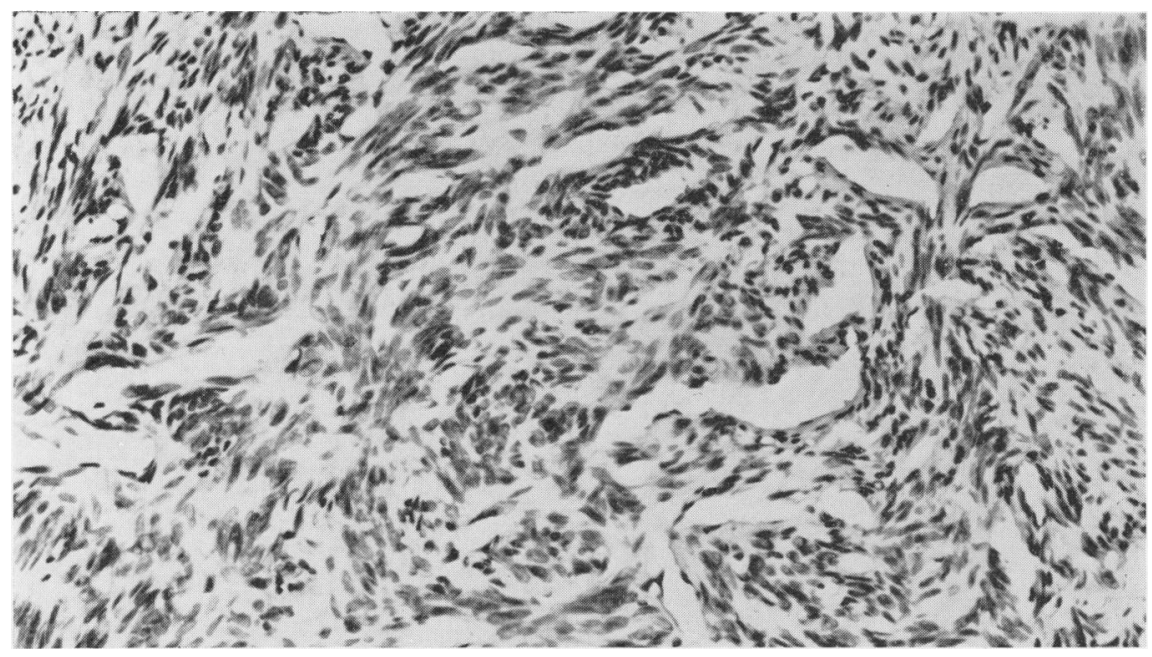

FIG. 6 Pseudo-haemangiopericytomatous pattern seen in one field of the tumour. Haematoxyliı and eosin. $\times \mathbf{I} 50$

The tumour is composed of a monomorphous population of cells that feature cytoplasmic filaments with fusiform densities, such as are characteristic of smooth muscle cells (Rhodin, $\hat{9} 62$ ) and represent modified Z-bands. The cells possess basement membrane and there is very little intervening interstitial collagen. Grapple plaques or marginal densities are conspicuous along the inside of the plasmalemma, as are pinocytotic vesicles. The tumour cells abut directly on the capillary passages without an intervening different population of cells (Figs 7 and 8, opposite and overleaf). The亏 absence of an elastica interna indicates that these are large-bore capillaries rather than arterioles.

\section{Discussion}

Electron microscopy was performed in this case with the intention of investigating the histogenesis of fibrous histiocytoma. We were surprised to discover that the tumour was a leiomyoma, on the basis of the unequivocal electron microscopic findings. Cytoplasmic filaments are found in tumours of Schwannian (Hilding and House, 1965) and meningeal (Napolitano, Kyle, and Fisher, I 964) origin, but these filaments do not possess fusiform densities, nor do they co-exist with plasmalemmal densities-features which are the salient characteristics of our tumour cells.

We went back to the light microscopic material and reviewed the findings with Dr. Raffaele Lattes of the Division of Surgical Pathology, at the Columbia University Department of Pathology. The cigar-shaped nuclei, the retraction of the cytoplasm around the nuclei which may be due to coagulation of myofilaments, the small amount of interfascicular collagen, the non-organoid deposition of reticulum, all favour the diagnosis of leiomyoma. The failure to demonstrate cytoplasmic filaments by light microscopic stains has been mitigated by electron microscopic demonstration of these filaments.

The diagnosis of a fibroblastic tumour is not supported by the dearth of intercellular collagen (Mortada, I97I). The initial impression of fibrous histiocytoma was based on the "storiform" pattern discerned in certain fields, where whirls of cells appeared to burst or nebulize out of a central focus (Stout and Lattes, I966; Vogel and Müller, I969). There were, however, no true histiocytic or plump cells in this tumour. It is interesting to note that dermatofibrosarcoma protuberans of the abdominal wall is considered a 


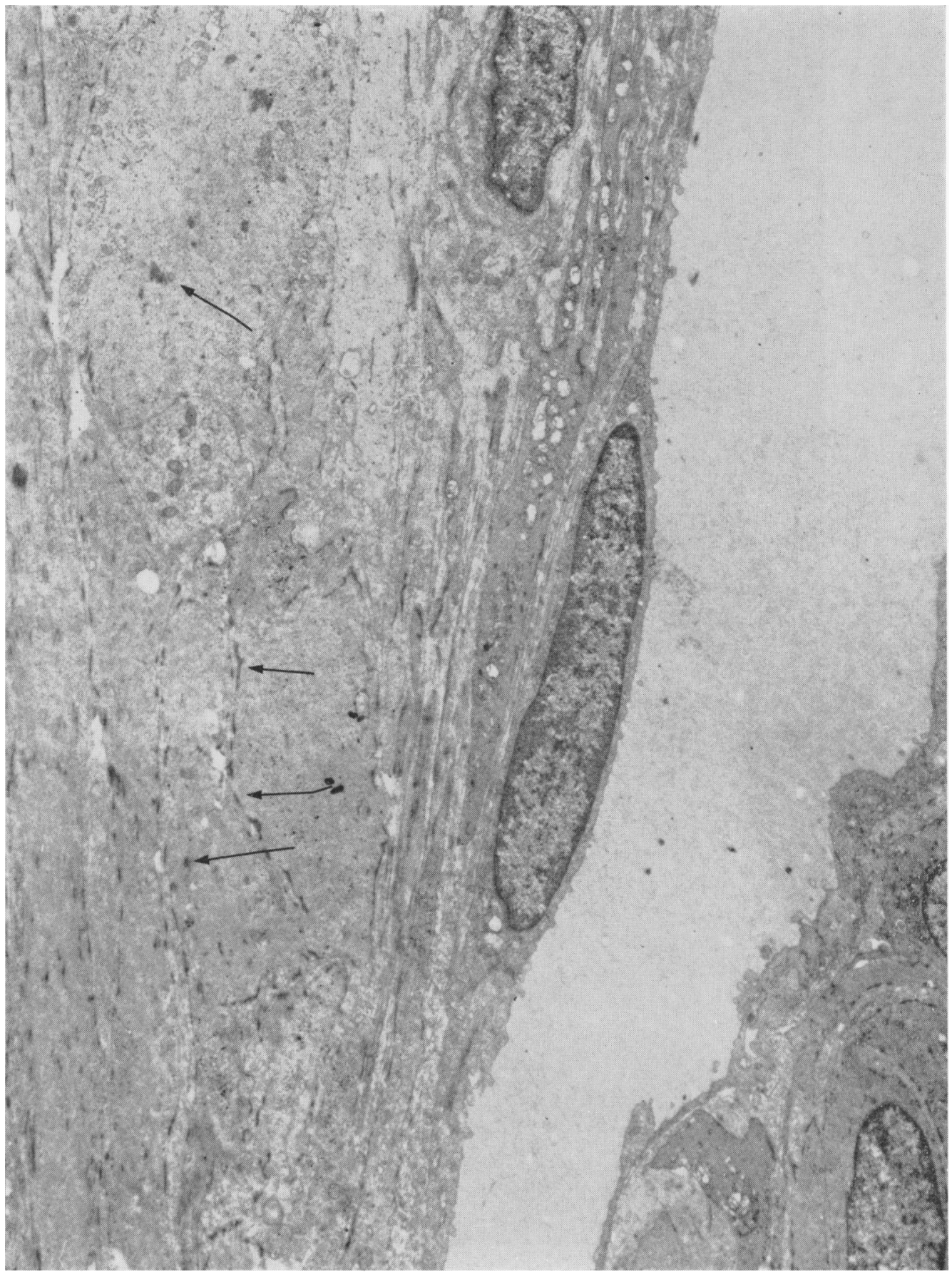

FIG. 7 Smooth muscle cells abutting on a capillary lumen. Arrows point to fusiform and plasmalemmal densities. $\times 4,250$ 


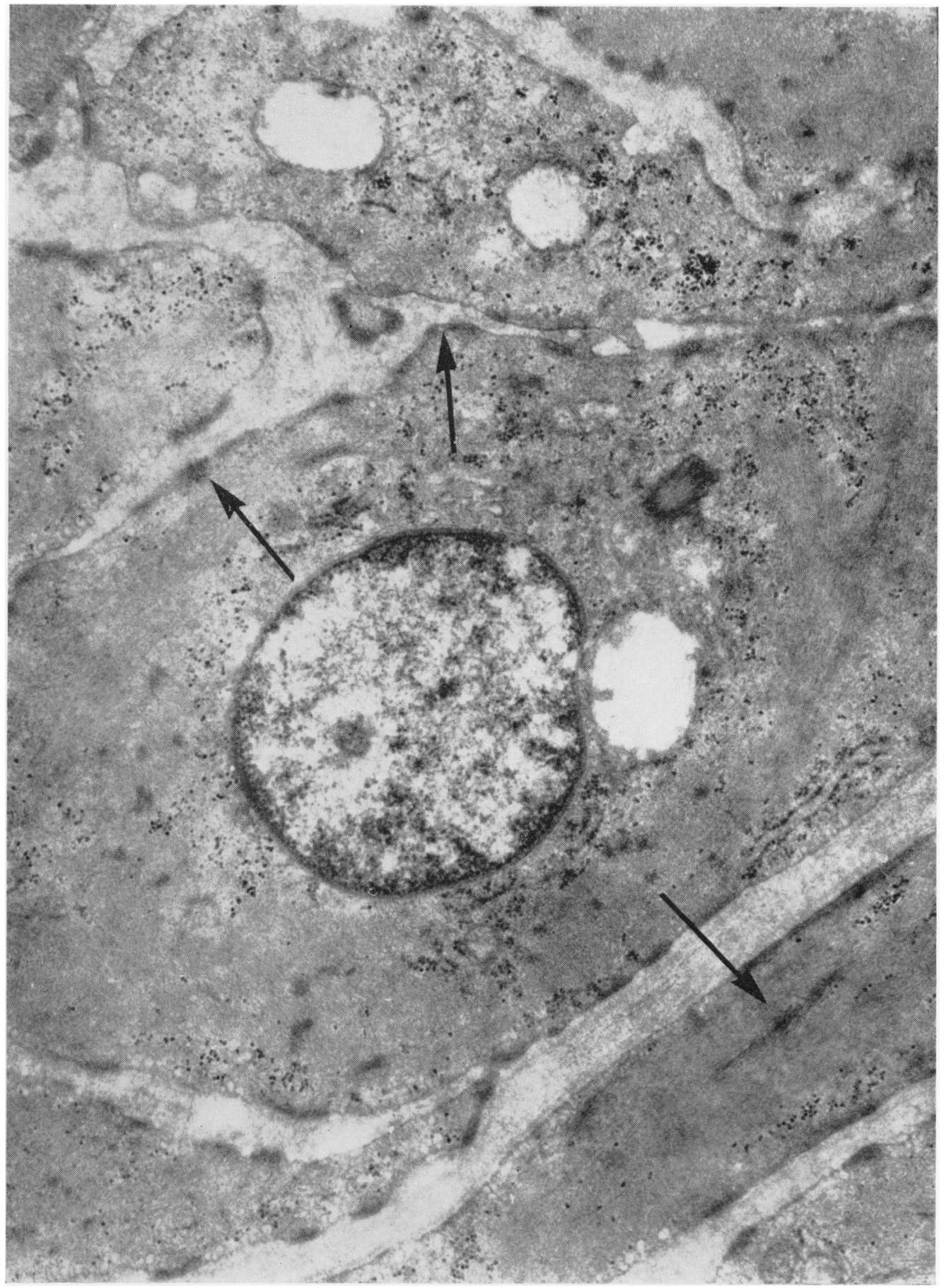

FIG. 8 Cytoplasmic filaments with fusiform densities, marginal plasmalemmal densities, and basement membrane formation are prominent features of the tumour cells. Arrows point to fusiform and plasmalemmal densities. $\times 24,000$

variant fibrous histiocytoma, even though this tumour is composed only of spindle cells, which, however, demonstrate the storiform arrangement. Electron microscopy of this 
tumour has also shown it to be more consonant with a fibroblastic tumour with no histiocytic features (Fisher and Vuzevski, 1968). Our feeling is that "fibrous histiocytoma" is a general designation embracing a variety of different tumour types, and that electron microscopy is necessary to separate the true histiocytic tumours from imitators composed of more homogeneous spindle tumour types (smooth muscle, fibroblastic, pericytic, Schwannian).

This case affords striking clinical and pathological correlations. The fossa in the central orbital roof indicates a long-standing benign process, such as a neurofibroma or a dermoid (or leiomyoma); its eccentricity from the lacrimal fossa fairly well exculpates the lacrimal gland. The ultrasonogram showed the tumour indenting the globe, thereby creating striae. It was sharply contoured, suggesting the presence of a capsule which was found at surgery. In contradistinction, fibrous histiocytomas, both benign and malignant, are not encapsulated. Both the ultrasonogram and the tomograms estimated the anteroposterior extent of the tumour to be $20-30 \mathrm{~mm}$., with a clear orbital apex, which were the findings at surgery. Finally, the profuse bleeding at surgery is accounted for by the generously interspersed dilated capillaries.

The histogenesis of this tumour must remain uncertain, but it possibly developed from vascular smooth muscle elements in the superior portion of the orbit. There appears to be a spectrum of tumours, ranging from the primarily vascular with a large component of smooth muscle cells in the walls and interluminal spaces (Wolter, ig65; Henderson and Harrison, i970) to rather solid smooth muscle tumours that do not feature a conspicuous vascular component (Nath and Shukla, i 963). The present tumour appears to comprise mostly solid smooth muscle.

The pericyte is a possible cell origin for all of these tumours. In his electron microscopic studies, Rhodin (1968) has shown that the pericyte evinces several evolutionary states, ranging from the poorly differentiated mesenchymal cell of capillary walls to the more highly differentiated smooth muscle cell of venular walls. Electron microscopic studies of haemangiopericytoma (Ramsey, I966; Murad, von Haam, and Murthy, I968) have shown that this tumour is composed of the more primitive mesenchymal cells rather than the differentiated smooth muscle cells found in our patient.

\section{References}

Fisher, E. R., and VUZevski, v. D. (1968) Amer. J. clin. Path., 49, I4 I

henderson, J., and harrison, e. (1970) Trans. Amer. Acad. Ophthal. Otolaryng., 74, 970

HILding, D., and house, w. (1965) 7 . Ultrastruct. Res., 12, 6 I I

MORTADA, A. (197I) Brit. J. Ophthal., 55, 350

MURAD, T., VON hAAM, G., and MURThy, s. N. (1968) Cancer (Philad.), 22, I 239

NAPOlitano, L., KYLE, R., and Fisher, E. R. (1964) Ibid., r7, 233

NATH, K., and Shukla, B. (1963) Brit. 7. Ophthal., 47, 369

OfFRET, G., and hAYe, c. (I97I) "Tumeurs de l'oeil et des annexes oculaires", p. 460. Masson,

Paris

RAmSEy, H. (1966) Cancer (Philad.), 19, 2005

REESE, A. B. (1963) "Tumors of the Eye", 2nd ed., p. 439. Harper and Row, New York

RHodin, J. (1962) Physiol. Rev., 42 (Suppl. 5), p. 48

(1968) 7. Ultrastruct. Res., 25, $45^{2}$

stout, A., and Lattes, R. (1966) 'Atlas of Tumor Pathology', 2nd ser., fasc. I, "Tumors of the

Soft Tissues", Armed Forces Institute of Pathology, p. 38-52; 58-63. Washington, D.C.

vogel, м. H., and müller H. (1969) Klin. Mbl. Augenheilk., I55, $55^{2}$

WOLTER, J. R. (1965) Eye Ear Nose Thr. Mthly, 44, $4^{2}$ 